\title{
Metal structural roofing with a flat truss with continuous chords as an enlarged assembly unit
}

\author{
Vadim Alpatov ${ }^{1, *}$ \\ ${ }^{1}$ Samara State Technical University Institute of Architecture and Civil Engineering, \\ Molodogvardeyskaya st. 194, 443001 Samara, Russia
}

\begin{abstract}
When building a new block of a health and recreation center, designer metal structures were used in the roofing coverage. The over covered three storey building consists of two blocks. It has a variable height and a mixed framework. Both building blocks were over covered with structural lattice roofing of similar design. When designing spatial structural roofing, the authors proposed a new design concept. The novelty of the design lies in the fact that a modified flat truss is used as the basic assembly unit of a spatial structure. To develop a spatial structure design the roof-girder trusses with continuous chords from rolled I-beams and a lattice from roll-welded sections with non gusset joists were used. They are well-known and work well in practice. When designing structural roofing, previously known trusses of the mentioned design were slightly modified. In particular, trusses with parallel chords were given greater camber $(2.5 \%$ instead of $1.5 \%$ ), the design of a supporting truss joist was changed and fixing elements for chord and lattice members joining trusses into a spatial structure were added to truss joists.
\end{abstract}

\section{Introduction}

Metal structures are well-known for their architectural expressiveness. This advantage determines in many respects the popularity of their application as roof-covering structures of public entertainment objects which are visible. Sports facilities, fitness centers, shopping centers and other buildings are in the sphere of application of structural roofing in civil engineering.

\section{Main Part}

When constructing the new building of one of the city's health and recreation centers in Samara, designer metal structures were used in the roofing coverage. The over covered three storey building consists of two blocks $(24 \times 30 \mathrm{~m}$ and $36 \times 18 \mathrm{~m})$. It has a variable height and a mixed framework. Both building blocks were over covered with structural lattice roofing of similar design.

*Corresponding author: avu75@mail.ru 
When designing spatial structural roofing, the authors proposed a new design concept. The novelty of the design lies in the fact that a modified flat truss is used as the basic assembly unit of a spatial structure. To develop a spatial structure design the roof-girder trusses [1] with continuous chords from rolled I-beams and a lattice from roll-welded sections with non gusset joists were used. They are well-known and work well in practice.

The trusses of mentioned design have a number of advantages:

1) the usage of I-beam cross-section as a truss chord allows the application of such structures in roofing without roof-bearers;

2) continuous chords have smaller effective lengths;

3) the usage of effective tubes as a truss lattice allows to achieve saving metal;

4) the joist connections without sheet gussets for combining a lattice and chords saves metal, which according to various sources can be from 10 to $20 \%$ of the whole truss weight for roof girder trusses. [2]

Continuous truss chords used as an assembly unit of spatial structure allows to use the advantages of factory precast structures in full. In particular these are the well-known advantages of reducing the labor intensivity when manufacturing structures at the factory before assembling them at the installation site; the use of the advantages of mass and in-line manufacturing, and reduction of the labor intensivity of pre-assembly works, etc. Economic and technical advantages of assembling structures from large size assembly units were mentioned in lots of publications, including publications by the authors [3] - [7].

When designing structural roofing, previously known trusses of the mentioned design were slightly modified. In particular, trusses with parallel chords were given greater camber than in the prototype $(2.5 \%$ instead of $1.5 \%)$, the design of a supporting truss joist was changed and fixing elements for chord and lattice members joining trusses into a spatial structure were added to truss joists.

The covering without roof bearers as an assembly unit is among the advantages of the designed structure solutions. To reduce the weight, the chord lattices of the structure are made thinned. The chord lattices contain only the minimum number of elements that join together flat trusses. The required quantity of joining chord elements is defined by the requirement to ensure geometric invariability of the structure in general.

The structure is intended for usage in a building with variable height, wherefore the possibility of accumulating a snow bag on the roofing was taken into account in the design. Anti-symmetrical load of considerable intensity due to the formation of a snow bag resulted in refusal to use the complete unification of assembly units. It was decided to design two types of flat trusses, which differ from each other in effective cross-sections of elements trusses that happen to be in the area of a snow bag and trusses that do not happen to be in the area of a snow bag. Taking into account significant snow load with a higher value of the snow accumulation coefficient in the snow bag area caused considerable increase in material consumption. Despite this, the previously mentioned advantages of the proposed design solution helped to retain acceptable technical and economic parameters of the structure. Weight parameters of proposed structure can be comparable to parameters of well-known standard structural designs.

\section{Conclusion}

The building with the structure proposed by authors consists of two thermal blocks of various height. Both blocks are over covered by the proposed structures. General view of the building with roofing in the form of spatial structures is presented in Figures 1 and 2. Projection views of structural design are presented in Figure 3. Average consumption of the metal for manufacturing metal roofing was $25 \mathrm{~kg} / \mathrm{m}^{2}$. 


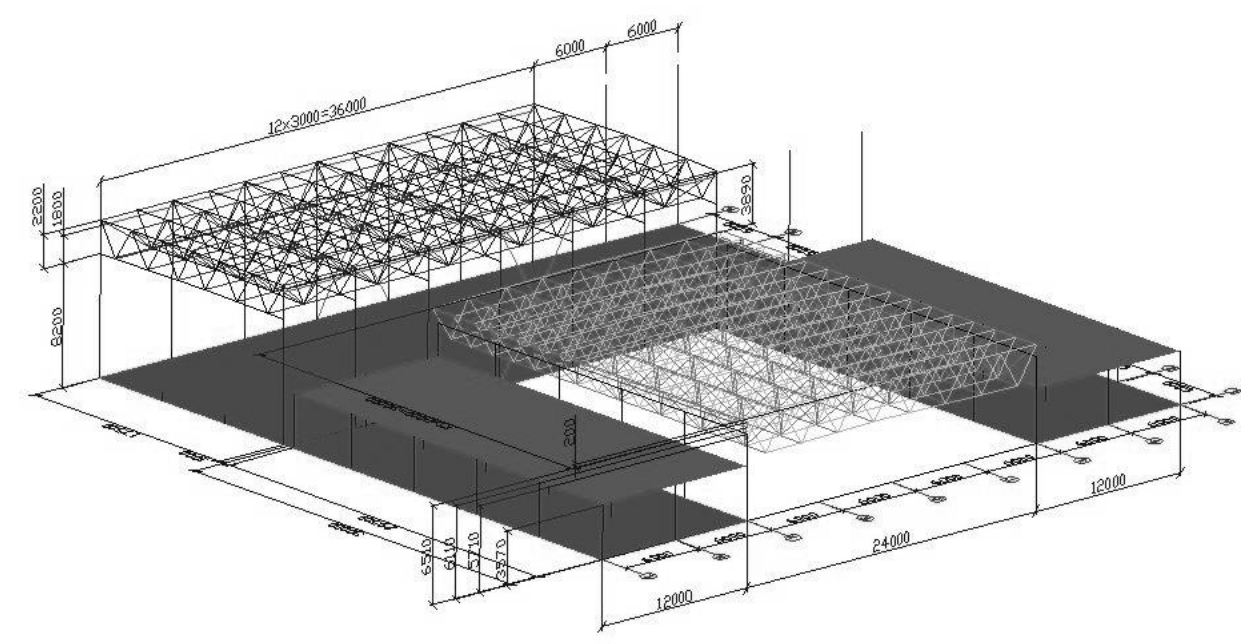

Fig. 1. General view of the building.

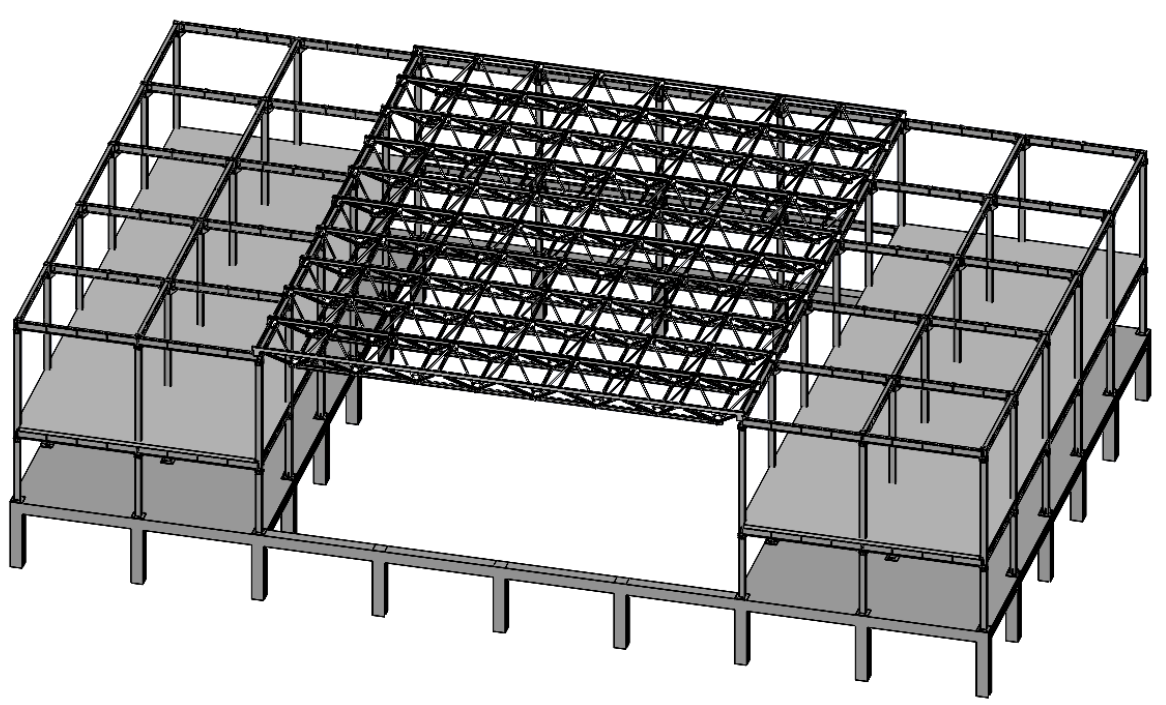

Fig. 2. Frame of the building block with structural roofing sized $24 \times 30 \mathrm{~m}$. 

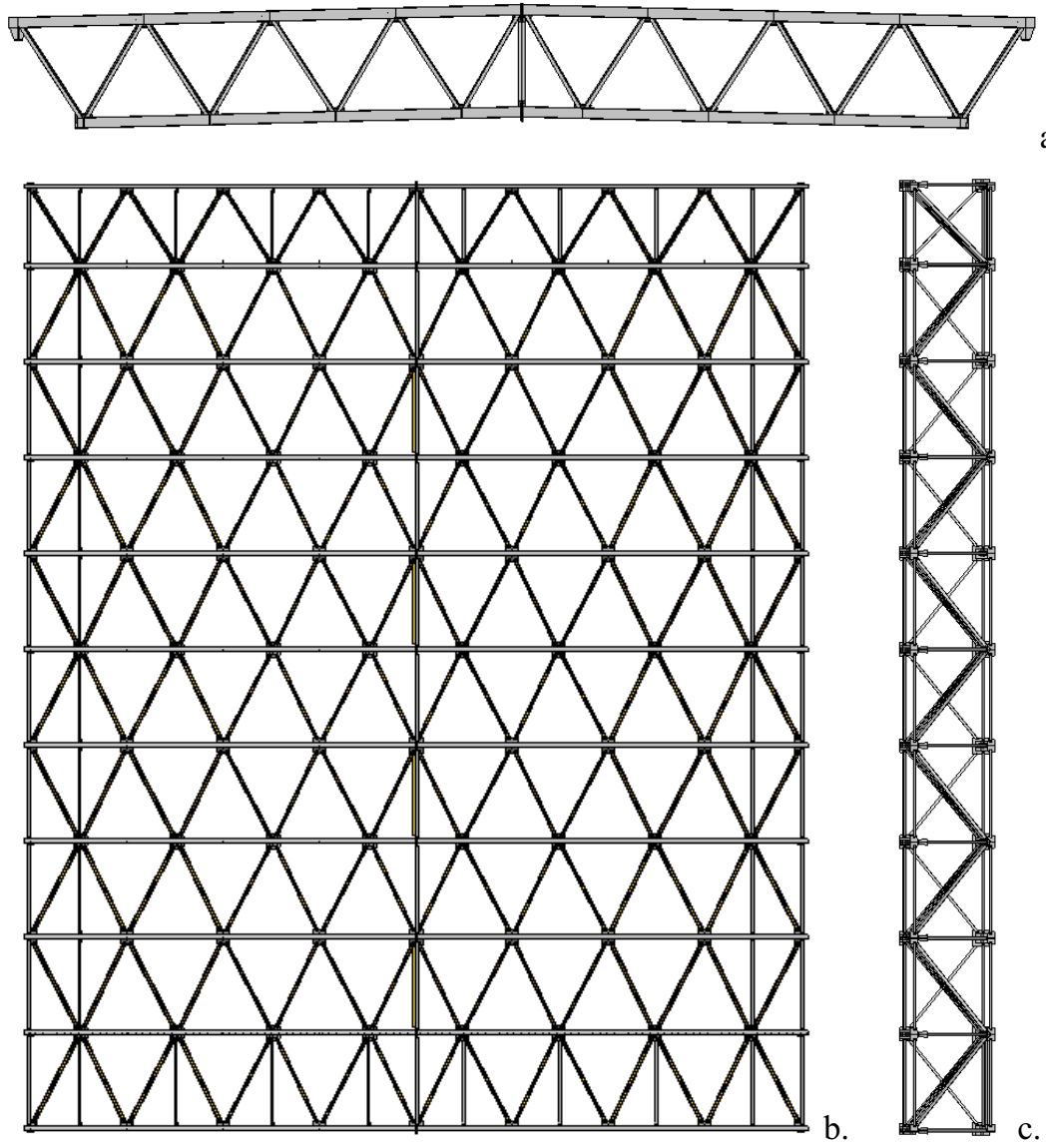

a.

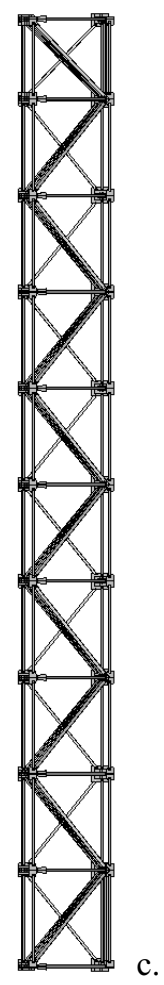

Fig. 3. Projection views of structural design.

a. - General view;

b. - Top view;

c. - Side view.

\section{References}

1. I. V. Levitanskiy, F.F. Kuklin, Sbornik nauchnyih trudov TsNIIproektstalkonstruktsii im. Melnikova, 52-61 (1984)

2. I.I. Ischenko, E.G. Kutuhtin, V.M. Spiridonov, Yu.N. Hromets, Light metal work of single-storey industrial buildings. Designer's Reference Book (Stroyizdat, Moscow, 1979)

3. V.Yu. Alpatov, I.S. Holopov, Framed structure from long-sized elements [Patent]: 33381: A utility model patent. - Russian Federation (2003)

4. V.Yu. Alpatov, Spatial frame structure [Patent]: 2213185: patent for the invention Russian Federation (2007)

5. V.Yu. Alpatov, I.S. Holopov, A.V. Solovev, Stroy-info. Informatsionniy byulleten 22(214), 7-10 (2003)

6. M.I. Balzannikov, V.Yu. Alpatov, I.S. Kholopov, A.A. Saharov, A.O. Lukin, MATEC Web Conf. 73, 1-6 (2016)

7. I.S. Kholopov, M.I. Balzannikov, V.Yu. Alpatov, A.V. Soloviev, Procedia Engineering 153, 277-282 (2016) 